previous work by Professor Dilman and others. The book offers a conceptually coherent account of insight and change appropriate to all forms of insightorientated psychotherapy. It also offers an interesting contribution to the ethical understanding of what takes place in these therapies.

DR DAVID ELWELL Registrar in Psychiatry Warneford Hospital Oxford

\section{Casebook on the Termination of Life- sustaining Treatment in the Care of the Dying}

Edited by Cynthia B Cohen, 160 pages, Bloomington and Indianapolis, USA, $\$ 25$ hbk, \$10.95 pbk, Indiana

University Press, 1988.

The authors of fast-selling paperbacks have one thing in common - they are all excellent storytellers. Knowledge of the practice of medicine is best learnt by reading patients' case-histories. There has been a need for a book on medical ethics based on real case-stories which can help junior and senior hospice or hospital staff as well as general practitioners in making decisions about the termination of life-sustaining treatment with dignity, thus making the end of life for a sufferer from a terminal illness as peaceful, painless and humane as possible. Dr Cohen, who is a philosophy teacher at Hahnemann University Medical School at Villanova University and also a lawyer, has fulfilled this need admirably. She is certainly a good storyteller. However, best-sellers are not always noncontroversial and this book, like many other books on ethics, has many debatable points, especially when it deals with the issue of the right to stop medical treatment for patients, knowing that this may mean their death.

An interesting style is adopted in this book. There are 26 case histories. Each case history is preceded by a moral dilemma for example, should economic considerations play a role in choices made by health professionals? Every case history is based on an actual situation then some relevant questions are posed for example, how and when diverse treatment modalities including respirators, blood transfusions, antibiotics and analgesics should or should not be used in that particular case. A commentary by a member of the Hastings Center research group then takes us through the maze of rational morality, highlighting the questions raised by each case, providing an ethical framework to answer them, suggesting a line of action that is within the range of American as well as English medicolegal systems, and surprisingly still leaving scope for discussion. The scenario is that of a classroom - $a$ lot is said informatively, concisely, interestingly, and within a short period of time - and the cases are designed to illuminate some ethical, medical, legal, and psychological contours of a particular dilemma.

The first chapter goes straight into the depth of rational morality and discusses the most hotly debated questions: When should a person be pronounced dead? Who should make these decisions - doctors and nurses, judges, the government, ethical committees, or patients and their families? Each chapter then takes a different angle and looks at the roles that are played or should be played by patients, families, physicians, nurses, lawyers, and health care administrators.

One chapter deals with the question of capacity and makes it clear that unless there is irresolvable disagreement between the physician, patient and surrogate about either the patient's capacity or the treatment alternative chosen, including the option of no life-sustaining treatment, there is no necessity for further consultation with an ethical committee or adjudication by the courts. However, resorting to these bodies in general should be reserved for cases where serious conflict or uncertainty persists about how to proceed.

There are chapters on moral dilemmas based on convictions such as: 'But he never told me not to', 'Was she ready to die', 'I have lived long enough', 'Life versus religious liberty', 'No patient of mine will ever starve to death', 'No place else to go', 'Trapped in the system', and 'When is patient care not cost-worthy?'. These are very educational. When is life worthwhile and when to call it a day? The author, supported by twenty-three commentators, has succeeded in answering this sixty-four-thousand dollar question and has yet left room for further discussion.

I recommend this American book to readers who are in the front-line in the care of dying patients - doctors and other health professionals in hospices, hospitals, and general practice throughout the Western world.

BASHIR QURESH General Practitioner 32 Legrace Avenue, Hounslow, London

\section{International Medical Malpractice Law}

Dieter Giesen, 923 pages, Tubingen, Dordrecht, Boston, London, DM380.00, hbk, JCB Mohr (Paul Siebeck) and Martinus Nijhoff, 1988.

There are, and probably always will be, conflicting values between the law and medical ethics. Indeed, neither the law nor medical ethics are, or are likely to become, wholly indisputable or clear let alone compatible with each other.

The medical profession have largely arrogated decisions to themselves, and the courts have largely not interfered, a least until now. The law has tended to limp or lag behind new developments such as IVF and all its implicationso Medical science and technology have developed very quickly, creating their own demand, creating new fashions, and medical ethics has also tended to limp and lag behind. If we can create embryos where we could not do so before, why not do so? If we can experiment on embryos where we could not do it before, why not do so? Research and science and technology are very important, they represent progress, do they not? They improve our quality of life, do they not? Or do they? We are in danger of unthinking capitulation to technology. Suppose the anaesthetist watches the machine monitor and not the patient, and does not see the warning signs on the patient?

Society, through Parliament, ought to face up to these issues, and not just pusillanimously do nothing and leave it all to the medical profession and the judiciary.

The patient is today much more aware, much more concerned about disclosure and autonomy, much more willing to sue, especially the seemingly faceless health department or hospital authority or medical professional body or insurers. However, the patient daring to sue faces considerable difficulties, such as getting disclosure, getting experts, and overcoming the burden of proof. 
In applying and developing the law the courts may be able to create and improve standards and to impose effective sanctions in appropriate cases. The public is rightly concerned with the dignity of the patient and the social desirability of compensation for the injured, hence the growing demand for some form of no-fault compensation. Instead of a forensic battle between the injured patient seeking compensation and the doctor seeking to protect his reputation and prestige, we need a system that both compensates the patient and protects the doctor from unfortunate attack upon his professional skill (subject to error though he is, like all of us).

The doctrine that the doctor knows best, indeed that only the doctor knows, that it is a matter solely within the clinical skill and judgement of the doctor, still largely survives. $\mathrm{He} / \mathrm{she}$ will decide whether a child shall be supplied with contraception; who shall be selected for kidney transplant; whether to apply chemotherapy; whether or not to keep the patient alive. In the United States of America the courts have intervened in such matters more readily and more decisively than in other countries.

A worrying new development, or rather discovery, is iatrogenic disease or illness caused or induced by the process of medical examination or treatment, for example radiography and drugs.

Incidentally, the effect or impact of medicine can perhaps be exaggerated. The quality of life has not improved that much. Life expectancy has barely increased. Heart disease and cancer are major unconquered causes of death.

It may be that we are facing a forensic crisis. The medical profession work in isolation, close ranks, maintain a conspiracy of silence, refuse to disclose what happened. The patient is largely powerless. In the adversarial system, each party, plaintiff and defendant, seeks for the expert witness favourable to his side, who will reject the unfavourable, so that in court the witness, expert though he may be, is seen as partisan, biassed, lacking in objectivity, a witness to be treated with scepticism. Where is the truly independent expert witness? Where is the well-qualified judge able competently and objectively and fairly to evaluate the evidence?

Professor Dieter Giesen is a scholar of high order. His mastery of the issues, his lucid exposition, and his enormous range of source material are most impressive. In addition to the discussion of these, and many other ethical problems, he has written at length and in depth on the civil liability of physicians and civil liability with regard to new methods of treatment and experimentation. The comparative material from the English-speaking world and from the continent of Europe, and indeed elsewhere, also marks out this study as of particular value.

ALEC SAMUELS

$\mathcal{F P}$, Barrister, BA (Cantab)

\section{Ethics, Technology and Medicine}

Edited by David Braine and Harry

Lesser, 138 pages, Aldershot, $£ 19.50$, hbk, Gower Publishing Company Limited, 1988

This is a difficult book for a mere doctor. Not only is the typesetting small and closely packed, the introduction, with its unsubstantiated implication that medicine has adopted a wholly 'technical attitude', implies a rather biased view. In addition the title and the book's claim to be '.... response to the moral problems caused by a rapid growth of technology in medicine and psychotherapy...', created an expectation that was never really fulfilled. There was relatively little specific reference to technology and the ultimate frustration came in David Lamb's statement when he was exploring the moral dilemma arising from the opportunity cost (although he did not acknowledge the opportunity lost to another potential patient) of extending the life of a single patient at some significant financial cost. He claimed '...It is not the task of moral philosophers to alleviate moral anxiety with references to economic reality; it is not their task to relieve moral anxiety at all'. Perhaps this is why I was frustrated by the various allegations throughout the book about doctors and their explicit and implicit intentions. Given that modern technology does indeed create moral problems, and that these are recognised by many doctors, I was searching for constructive help from the moral philosophers: at the very least I looked for some help in formulating the frameworks within which moral decisions can be made.

Despite my overall frustration this book did indeed provide some thoughtful direction although not in the areas I had expected. It is a series of essays beginning with a complex analysis by David Braine of 'Human Animality'. Simon Glen's contribution on 'Objectivity and Alienation' identifies the obscene disparity between current human knowledge and technological capacity and the resultant threats to survival from widespread starvation, resource depletion, pollution and nuclear weaponry. He identifies man's increasing alienation from his roots and his failure to 'be-inthe-world with others' which results in a hedonistic merry-go-round of getting and spending. Harry Lesser's 'Technology and Medicine: Means and Ends' identifies the vastly increased scope of medical practice and the resultant change in expectations of both doctors and patients. This essay is better at identifying that doctors differ in their approaches but I was confused by his restriction of 'medicine' to mean the 'removal of undesirable physical conditions' followed by a later condemnation of such a limited approach. The task of helping people/ patients to understand themselves and their relations with others is something different which he defines as argument for holistic medicine thatco must embrace both.

John Hostler's 'The Sanctity of Life and the Sanctity of Death' emphasises the importance of allowing patients to know and prepare themselves for death; David Lamb's 'Down the Slippery Slope' ranges from Nazi eugenic killings to cost/benefit issues and warns how the 'cunning of reason' can create a thin end of the wedge for a gradual change in the moral climate within which decisions are made. Ruth Chadwick's and Heather Draper's helpful contributions on 'Genetic Improvement' and 'Transexuals and Werewolves' respectively, are the only essays that specifically address the ethical issues raised by our modern and future technological capacity in medical practice. David Linton explores 'Why is Pornography Offensive?' which is interesting but I'm not sure why it is here and David Smail finishes with 'Technology and Psychotherapy' in which he explains that technology plays a minimal role. Indeed he emphasises that a 'magical' technological response, capable of alleviating human distress, is highly unlikely and the book concludes with his salutory reminder that psychological damage will only be avoided 'through our developing a society in which we treat each other with greater care and kindness'. 